\title{
Neural Precursor Death Is Central to the Pathogenesis of Intestinal Aganglionosis in Ret Hypomorphic Mice
}

\author{
Toshihiro Uesaka and Hideki Enomoto \\ Laboratory for Neuronal Differentiation and Regeneration, RIKEN Center for Developmental Biology, Kobe 650-0047, Japan
}

The RET tyrosine kinase is required for the migration, proliferation, and survival of the enteric neural crest-derived cells (ENCCs) that form the enteric nervous system (ENS). Hypomorphic RET alleles cause intestinal aganglionosis [Hirschsprung disease (HSCR)], in which delayed migration and successive nonapoptotic ENCC death are considered to be major contributory factors. The significance of ENCC death in intestinal aganglionosis, however, has remained unclear. We show that elevated expression of Bcl-xL inhibits ENCC death in both Ret-null and hypomorphic states. However, the rescued Ret-null mice showed ENS malfunction with reduced nitric oxide synthase expression in colonic neurons, revealing the requirement of RET for neuronal differentiation. In contrast, the inhibition of cell death allows morphologically and functionally normal ENS formation in Ret hypomorphic mice. These results indicate that ENCC death is a principal cause of intestinal aganglionosis in a Ret hypomorphic state, and suggest that the inhibition of cell death is a route to the prevention of HSCR.

\section{Introduction}

Hirschsprung disease (HSCR), or congenital intestinal aganglionosis, is found in approximately 1 in every 5000 live births, affecting more males than females (4:1 ratio). The most common form of the disease is the short-segment type in which the enteric ganglia are absent only in the distal colon. The aganglionic colon is incapable of peristalsis, resulting in severe constipation or lethal intestinal obstruction (Badner et al., 1990; Skinner, 1996; Parisi and Kapur, 2000; Amiel et al., 2008). RET is the major gene involved in HSCR. Nearly all HSCR patients harbor either a heterozygous mutation of the coding region (Angrist et al., 1995; Attie et al., 1995; Seri et al., 1997; Hofstra et al., 2000) or, more often, a heterozygous or homozygous hypomorphic allele located in a conserved enhancer sequence in intron 1 (Emison et al., 2005; Grice et al., 2005). In particular, a hypomorphic allele of RET accounts for the majority of isolated HSCR, constituting $70 \%$ of all HSCR cases.

Activation of the RET receptor occurs upon self-dimerization, which is induced by binding of glial cell line-derived neurotrophic factor (GDNF) family ligand to its cognate receptor, glycosylphosphatidylinositol-anchored coreceptor GDNF family receptor $\alpha(\mathrm{GFR} \alpha)$ (Baloh et al., 2000; Airaksinen and Saarma, 2002; Burzynski et al., 2009). RET signaling regulates multiple aspects of the development of the enteric nervous system (ENS), including cell proliferation (Chalazonitis et al., 1998; Hearn et

\footnotetext{
Received Dec. 16, 2009; revised Feb. 11, 2010; accepted Feb. 18, 2010.

This work was supported by Grants-in-Aid for Scientific Research (B) 21390122 (to H.E.) and (C) 20590204 (to T.U.) from the Ministry of Education, Science, Sports, and Culture, Japan. We are indebted to Hitoshi Niwa for providing us with EB3 embryonic stem cells. We also thank members of the Enomoto laboratory and the Laboratory for Animal Resources and Genetic Engineering for excellent technical assistance.

Correspondence should be addressed to Hideki Enomoto, Laboratory for Neuronal Differentiation and Regeneration, RIKEN Center for Developmental Biology, 2-2-3 Minatojima-Minamimachi, Chuo-ku, Kobe 650-0047, Japan. E-mail: enomoto@cdb.riken.jp.

DOI:10.1523/JNEUROSCI.6244-09.2010

Copyright $\odot 2010$ the authors $\quad 0270-6474 / 10 / 305211-08 \$ 15.00 / 0$
}

al., 1998; Taraviras et al., 1999; Gianino et al., 2003), migration (Young et al., 2001; Natarajan et al., 2002), differentiation (Taraviras et al., 1999), and survival (Taraviras et al., 1999). Mice homozygous for Ret deletion show total intestinal aganglionosis (Schuchardt et al., 1994) caused by impaired migration and apoptosis of immature enteric neural crest-derived cell (ENCCs). In contrast, inactivation of Ret or Gfr 1 in later ENS development causes nonapoptotic death of enteric neurons in the distal colon, leading to colonic aganglionosis (Uesaka et al., 2007, 2008). Nonapoptotic death of enteric neurons also occurs under primary culture conditions. Enteric neurons isolated from embryonic hindgut die after GDNF deprivation, which cannot be prevented by either pan-caspase inhibitor or Bax deficiency (Uesaka et al., 2007). The molecular mechanism underlying cell death remains unclear. To date, only Bcl-xL overexpression has been shown to be able to rescue enteric neuronal death induced by GDNF deprivation (Uesaka et al., 2007).

A hypomorphic Ret mutation in mouse reproduces crucial genetic and phenotypic features of isolated HSCR, including incomplete penetrance, tendency toward male preponderance, and colonic aganglionosis with no other developmental deficits (Uesaka et al., 2008). Importantly, delayed migration and subsequent nonapoptotic death of ENCCs are considered to be the major causes of colonic aganglionosis in a Ret hypomorphic state. The contributory levels of ENCC death in colonic aganglionosis, however, remain unclear.

Here, we report a successful genetic intervention against enteric neuron death in vivo. Mice engineered to express elevated levels of Bcl-xL conferred resistance to cell death to ENCCs in both Ret-null and hypomorphic states. However, Ret-deficient ENCCs that had escaped from cell death did not undergo normal differentiation and failed to constitute a functional ENS. In contrast, rescued ENCCs in Ret hypomorphic mice completed migration, albeit in a delayed manner, and formed a functional ENS. 
The results demonstrate the requirement of RET in neuronal differentiation and ENS function and suggest that cell death, not migratory delay, of ENCCs is the principal cause of isolated HSCR. They also reveal a great deal of the plasticity of Ret hypomorphic ENCCs, which cells can form a functional ENS so long as their survival is ensured, a crucial finding for developing novel strategies toward the prevention of HSCR.

\section{Materials and Methods}

Mice. The Ret ${ }^{f l o x}$ and $R e t^{\text {Ret9/ - }}$ mice have been described previously (Uesaka et al., 2008). In this study, Ret heterozygous mice $\left(\operatorname{Ret}^{T L Z /+}\right)$ (Gould et al., 2008) are referred to as $\operatorname{Ret}^{+/-}$. The CAGGCre-ER and Bax ${ }^{-1-}$ mice were obtained from The Jackson Laboratory. Ret-Bcl- $x L$ allele was generated by knocking a gene cassette composed of human $B c l-x L$ cDNA with SV40 intron poly(A) and floxed neomycin resistance marker (Neo) into the first coding exon of the Ret gene in a manner that disrupts expression of the endogenous mouse Ret. This strategy was identical to that described previously (Enomoto et al., 2001). Primer sequences for genotyping of $\operatorname{Ret}^{B c l-x L}$ mice were as follows: $\operatorname{Ret}^{B c l-x L}$ forward, $5^{\prime}$ CGAGACCCGCCTGCTCCTCAACCGC-3'; wild type (WT) reverse, $5^{\prime}$ AGCGCTAACTTCACCCCGGCCCCTACCGTC-3'; mutant reverse, $5^{\prime}$-CACTGGGGGTCTCCATCTCCGA-3'. Mice used for this study were kept on a mixed 129/Sv $\times$ C57BL/6 background. All animal experiments were approved by the Animal Research Committee of the RIKEN Center for Developmental Biology and were performed in accordance with RIKEN guidelines for animal and recombinant DNA experiments.

Histological analysis. Immunohistochemistry and acetylcholinesterase (AChE) histochemistry were performed as described previously (Uesaka et al., 2007). We used the following primary antibodies: rabbit antibody to PGP9.5 (1:1000, Ultraclone), rabbit antibody to S100B (1:500, Lab Vision), chicken antibody to GFP (1:1000, Aves Labs), rabbit antibody to neuronal NO synthase (NOS) (1:500, Millipore), rabbit antibody to calretinin (1:2000, Millipore), rabbit antibody to calbindin (1:1000, Millipore), rabbit antibody to Bcl-xL (1:500, Cell Signaling Technology), and goat antibody to Sox10 (1:500, Santa Cruz Biotechnology), respectively. We used the appropriate secondary antibodies (1:500) conjugated to Alexa 488, Alexa 594, Alexa 633, or Alexa 647 (Invitrogen).

We took photomicrographs with Zeiss LSM5 PASCAL confocal microscope, Zeiss Axioskop 2 FS plus with a digital camera AxioCam HRc (Zeiss), or a Leica MZ FLIII with a digital camera AxioCam MRc5 (Zeiss).

Real-time quantitative RT-PCR analysis. Total RNA from myenteric plexus muscle layers of intestine was reverse transcribed using SuperScript III (Invitrogen), and $B c l-x L$ mRNA sequences were quantified by real-time PCR in a 7500 real-time PCR system (Applied Biosystems) with 100 nм primers in Power SYBR Green PCR Master Mix (Applied Biosystems). We used the quantity value of $\beta$-actin RNA levels in each sample as a normalizing control. The primers used for human and mouse $\mathrm{Bcl}$ $x L$ and human RET mRNA quantification were as follows: $B c l-x L$ forward, 5'-GGCACTGTGCGTGGAAAGCGTA-3'; $B c l-x L$ reverse, 5' -CCGCCGTTCTCCTGGATCCA-3'; human RET forward, 5' -GTGTGAGTGGAGGCAAGGAG-3'; human RET reverse, 5' -GTCCTGAGGGCAAATGTTGA-3' . Melting curve analysis ensured exclusion of primers from each analysis.

Cell culture. Primary culture of enteric neurons was prepared as described previously (Uesaka et al., 2007). Briefly, hindgut dissected from mouse embryos [embryonic day 15.5 (E15.5)] were treated with collagenase/dispase $\left(1 \mathrm{mg} / \mathrm{ml}\right.$, Roche) for $15 \mathrm{~min}$ at $37^{\circ} \mathrm{C}$. The cells were dissociated by repeated pipetting and $1 \times 10^{4}$ cells were plated onto a single well of an 8 -well slide coated with poly-D-lysine $(0.1 \mathrm{mg} / \mathrm{ml})$ and laminin $(20 \mu \mathrm{g} / \mathrm{ml})$. The culture medium contained DMEM low (Invitrogen) with $1 \% \mathrm{~N}-2$ supplement, 2\% B-27 supplement (Invitrogen), and penicillin/streptomycin (Meiji Seika). Cells were cultured for $2 \mathrm{~d}$ in the presence of GDNF $(100 \mathrm{ng} / \mathrm{ml})$ and then switched to medium containing either GDNF-neutralizing antibodies (no further addition of GDNF; GDNF deprivation) or GDNF (100 ng/ml; control).

Determination of the frequency, weight, and water content of stool. Each animal was provided unlimited access to water and food. During the course of a $1 \mathrm{~h}$ observation period, stools were collected immediately upon defecation and sealed in preweighed tubes. The frequency of defecation and the wet and dry weights of collected stool pellets were measured. The difference between wet and dry weights of stool was used to compute the stool water content.

Statistical analyses. Data are means \pm SEM. For all experiments, we calculated the difference between groups with the Mann-Whitney $U$ test. Survival data were plotted by the Kaplan-Meier method and analyzed by the log-rank test using GraphPad Prism5 software. We considered all $p$ values $>0.05$ not significant.

\section{Results}

\section{Enteric neuronal loss following Ret inactivation is prevented} by $B c l-x L$ expression but not by Bax deletion

Isolated HSCR is highly associated with hypomorphic mutations in RET. In mouse, hypomorphic Ret alleles affect both migration and survival of ENCCs and result in colonic aganglionosis. To elucidate the degree of the contribution of ENCC death to the HSCR-like phenotype, we developed a system by which ENCC death can be prevented in mice. Based on in vitro findings that the overexpression of $\mathrm{Bcl}-\mathrm{xL}$ rescues the death of GDNF-deprived enteric neurons (Uesaka et al., 2007), we attempted to elevate the level of Bcl-xL expression in ENCCs by knocking $B c l-x L$ cDNA into the Ret locus (Fig. 1A). This targeting strategy was used previously to generate Ret-null mice $\left(\right.$ Ret $\left.^{\text {CFP/CFP }}\right)$ in which RET expression was replaced by cyan fluorescent protein (CFP) (Uesaka et al., 2008). The insertion of Bcl-xL disrupted the Ret locus as seen in Figure $1 B$, top and bottom (showing Ret-null phenotype, including the absence of enteric ganglia and agenesis of kidney, respectively, in $\operatorname{Ret}^{C F P / B c l-x L}$ mice) but allowed expression of Bcl-xL under the Ret promoter (Fig. $1 A$ ). In the enteric plexus of $\operatorname{Ret}^{B c l-x L /+}$ mice at postnatal day 60 (P60), there was no increase in enteric neuron numbers (supplemental Fig. 1, available at www. jneurosci.org as supplemental material), but the level of $B c l-x L$ gene expression at $\mathrm{P} 0$ was elevated approximately twofold (normalized values of $B c l-x L$ mRNA in WT and $\operatorname{Ret}^{B c l-x L /+}$ mice were 2.26 and 1.27, $n=3$ ). Furthermore, a marked increase in Bcl-xL protein levels was observed in enteric neurons of $\operatorname{Ret}^{B c l-x L /+}$ fetuses (supplemental Fig. 2, available at www.jneurosci.org as supplemental material). To assess whether this elevated level of $\mathrm{Bcl}-\mathrm{xL}$ expression can exert prosurvival actions, we used an in vitro paradigm in which enteric neuronal death can be induced by GDNF deprivation. Enteric neurons were isolated from E15.5 hindgut, cultured in the presence of GDNF for $2 \mathrm{~d}$, and then subjected to GDNF withdrawal. While $\sim 70 \%$ of enteric neurons from WT hindgut died after GDNF deprivation, Ret $^{B c l-x L /+}$ enteric neurons were completely protected from cell death (Fig. $1 C, D$ ), indicating that the elevation of $\mathrm{Bcl}-\mathrm{xL}$ expression by the Ret-Bcl-xL allele is protective against enteric neuronal death in vivo.

To assess whether $\mathrm{Bcl}-\mathrm{xL}$ can inhibit enteric neuronal death in vivo, we determined the effect of $\mathrm{Bcl}-\mathrm{xL}$ on enteric neuronal loss resulting from the conditional ablation of Ret. Mice carrying a conditional allele of $\operatorname{Ret}\left(\operatorname{Ret}^{\text {flox }}\right)$ (Uesaka et al., 2008) were mated to $\operatorname{Ret}^{+/-}$(Gould et al., 2008) or Ret ${ }^{B c l-x L /+}$ mice harboring the CAGGCre-ER transgene. Treatment of pregnant mothers with 4-hydoxytamoxifen (4-OHT; $0.5 \mathrm{mg}$ per mouse) at E15.5 induced Cre activity to delete the floxed Ret, which was monitored, as described previously (Uesaka et al., 2008), by induction of CFP expression in the fetuses, and the fetal gut was examined at E18.5. Numerous $\mathrm{CFP}^{+}$enteric neurons were found in $\operatorname{Ret}^{\mathrm{CFP} /+}$ : CAGGCre-ER (control) colon (Fig. 2A, left), while very few enteric neurons were detected by CFP or PGP9.5 staining in Ret $^{C F P /-}: C A G G C r e-E R$ (cKO) colon (Fig. $2 \mathrm{~A}$, right). In contrast, in $\operatorname{Ret}^{C F P / B c l-x L}: C A G G C r e-E R(\mathrm{cKO} / \mathrm{Bcl}-\mathrm{xL})$ fetuses, Ret-deficient enteric neurons survived in the colon (Fig. $2 B$ ), and $\sim 60 \%$ of 
A

Ret locus
Homologous
recombinant

$B c l-x L$ knock-in (null allele)

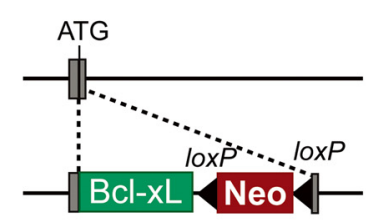

$\downarrow$ Cre recombination $\mathrm{Bcl}-\mathrm{xL}$
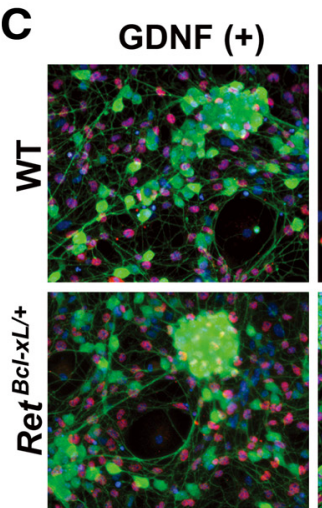

PGP9.5/Sox10/Hoechst
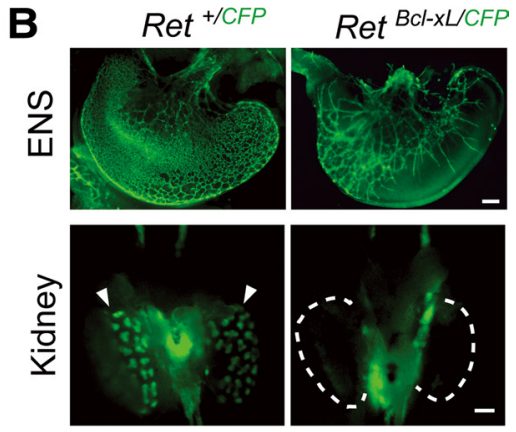

D

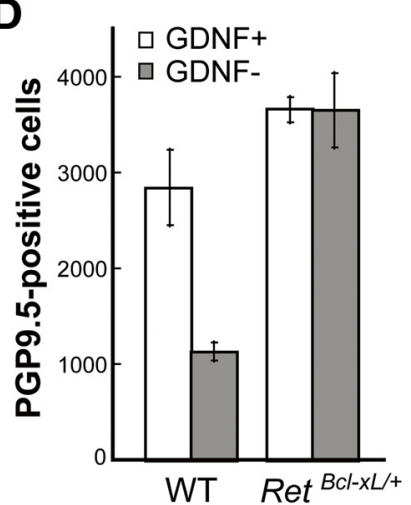

Figure 1. Generation of mice expressing $B C l-x L$ under the Ret promoter. $A$, The targeting approach to generate Ret-BCl-XL allele. Exon 1 is shown as gray box. The homologously recombined construct contains the wild-type human $B C l-x L C D N A$ (green box) and floxed Neomycin resistance expression cassette (Neo, red box; loxP, black triangle). Activation of Cre recombinase resulted in removal of the floxed Neo. B, Phenotype of Ret ${ }^{B(-x / / C F P}$ fetuses was identical to that of Ret-deficient fetuses. (FP fluorescence readily revealed the presence of ENS precursors and branching ureteric buds (arrowheads) in $\operatorname{Ret}^{(F P /+}$ fetuses (left), whereas no functional kidneys and ENS were observed in Ret ${ }^{B C-x L / C F P}$ fetuses (right) at E12.5. C, Elevated expression of BCl-xL prevents death of GDNF-deprived enteric neurons. Enteric neurons isolated from E15.5 WT and $\mathrm{Ret}^{B \mathrm{Cl}-\mathrm{xL} /+}$ hindgut were cultured for $2 \mathrm{~d}$ and then switched to GDNF-deprived conditions. Surviving neurons $\left(\mathrm{PGP} 9.5^{+}\right)$were counted $48 \mathrm{~h}$ after GDNF deprivation. $D$, Quantification of surviving enteric neurons. PGP9.5-positive neurons were counted. Error bar indicates SEM $(n=3)$. Scale bars; $\boldsymbol{B}, 200 \mu \mathrm{m} ; \boldsymbol{C}, 100 \mu \mathrm{m}$.

cKO/Bcl-xL mice displayed apparently normal ENS formation (Fig. 2C). Thus, elevated expression of Bcl-xL allows Retdeficient colonic neurons to survive in vivo.

In most parts of the nervous system, programmed cell death depends on the presence of Bax (Deckwerth et al., 1996; Miller et al., 1997; White et al., 1998). The deletion of Bax has been shown to significantly reduce neuronal death in several apoptosis paradigms, including neurotrophic factor deprivation (Deckwerth et al., 1996) and Bcl-xL deficiency (Shindler et al., 1997). However, Bax deficiency failed to affect the survival of enteric neurons in the developing ENS (Gianino et al., 2003), and GDNF-deprived enteric neurons died by a Bax-independent mechanism in vitro (Uesaka et al., 2007). We therefore investigated the potential involvement of Bax in enteric neuronal loss following conditional inactivation of Ret in mice. Massive enteric neuronal loss was observed even under the Bax-deficient condition (Fig. 2D). Thus, Bax deletion does not effectively attenuate enteric neuronal loss following Ret inactivation, indicating that enteric neurons die in a Bax-independent mechanism in vivo.

\section{Rescued Ret-deficient neurons fail to constitute a functional ENS}

While nearly all enteric neurons died in the distal colon of Ret cKO mice, enteric neurons in $\mathrm{cKO} / \mathrm{Bcl}-\mathrm{xL}$ mice survived in the absence of Ret. Although the degree of the rescue varied among animals, apparently normal ENS formation was observed in

$\sim 60 \%$ of Ret cKO/Bcl-xL mice (Fig. $2 C$ ). However, almost all $\mathrm{cKO} / \mathrm{Bcl}-\mathrm{xL}$ mice tended to be smaller than their control littermates (average body weight at 1 month: $14.3 \pm 0.3$ vs $11.0 \pm 1.5 \mathrm{~g}$ in control vs $\mathrm{cKO} / \mathrm{Bcl}-\mathrm{xL}$ mice), suggesting functional deficits in the rescued ENS in $\mathrm{cKO} / \mathrm{Bcl}-\mathrm{xL}$ mice. To explore this possibility, we performed a functional assay combined with more detailed immunohistochemical examination of the ENS, and the results were evaluated using only $\mathrm{cKO} / \mathrm{Bcl}-\mathrm{xL}$ mice, which display normal numbers of enteric neurons (control and cKO/Bcl-xL were $847 \pm 24$ and $896 \pm 40$ cells per $\mathrm{mm}^{2}$, respectively, $n=5$ ) and glial cells (control and $\mathrm{cKO} / \mathrm{Bcl}-\mathrm{xL}$ were $1195 \pm 60$ and $1192 \pm 43$ cells per $\mathrm{mm}^{2}$, respectively, $n=3$ ). Stool frequency, wet stool weight, and water content of stools were all significantly lower in $\mathrm{cKO} / \mathrm{Bcl}-\mathrm{xL}$ than in control mice $[2.3 \pm 0.4$ versus $4.0 \pm 0.4$ pellets $/ \mathrm{h}(p<0.05]), 25.2 \pm 2.9$ versus $49.6 \pm 3.1 \mathrm{mg}(p<0.05)$, and $8.3 \pm 0.7$ versus $13.8 \pm 0.9 \mathrm{mg}(p<0.05)$, respectively, $n=4)$. In two of five $\mathrm{cKO} /$ $\mathrm{Bcl}-\mathrm{xL}$ mice, we observed hard feces accumulated in the distal colon (Fig. 3A). Fiber density revealed by AChE staining was comparable in $\mathrm{cKO} / \mathrm{Bcl}-\mathrm{xL}$ and control colon (Fig. $3 B, C$ ). Neuronal subtypes were examined by immunohistochemistry (Fig. 3D,E) against calretinin (excitatory motor and a part of intrinsic primary afferent neurons) (Sang and Young, 1998; Qu et al., 2008), NOS (inhibitory motor neurons) (Lyster et al., 1995; Sang et al., 1997), and calbindin (intrinsic primary afferent neurons) (Qu et al., 2008). The proportion of calretinin- or calbindin-positive neurons to CFP-positive (rescued Ret-null) neurons remained unchanged in $\mathrm{cKO} / \mathrm{Bcl}-\mathrm{xL}$ colon as compared with control. However, a striking decrease was observed in the proportion of NOSexpressing neurons to the rescued Ret-null neurons in $\mathrm{cKO} /$ $\mathrm{Bcl}-\mathrm{xL}$ colon. The proportion of NOS/CFP neurons remained unaltered in the small intestine (Fig. 3E). These results indicate that RET provides crucial support for $\mathrm{NOS}^{+}$colonic neurons and suggest that the decreased NOS neuron density in the colon leads to intestinal dysfunction. Together, these results indicate that, although elevated Bcl-xL expression protects Ret-deficient enteric neurons against cell death, it is insufficient for the ENS to fully mature and function in a Ret-null state.

\section{Elevated expression of Bcl-xL in ENCCs suppresses the HSCR-like phenotype in Ret hypomorphic mice}

We finally moved on to assess the impact of prosurvival actions of $\mathrm{Bcl}-\mathrm{xL}$ in a HSCR state. To this end, we crossed Ret $t^{B c l-x L /+}$ mice to $R e t^{9 /+}$ mice. $R e t^{9 /-}$ mice carry a hypomorphic allele of Ret and display distal colonic aganglionosis with incomplete penetrance and overall incidence of $38 \%$ ( 8 of 21 ). The other Ret-dependent forms of organogenesis, including kidney development and motor innervation, proceed normally in these mice. These genotypic and phenotypic features closely resemble those of isolated HSCR, indicating that $\mathrm{Ret}^{\mathrm{9}-}$ mice serve as one of the best models of HSCR 
(Uesaka et al., 2008). To our surprise, the Ret-Bcl- $x L$ allele almost completely suppressed intestinal aganglionosis phenotype (Fig. 4). Among $51 \mathrm{Ret}^{9 / B c l-x L}$ mice examined, 50 had normal ENS, and intestinal aganglionosis (short segment) was detected in only one mouse (the incidence in $R e t^{9 /-}$ versus $\operatorname{Ret}^{9 / B c l-x L}$ mice, $38 \%$ versus $2 \%$, respectively, $p<0.0001)$.

In $R e t^{9 /-}$ fetuses, a delay in hindgut colonization by ENCCs is first discernible (most prominent after E12.5; compare WT and $\mathrm{Ret}^{9 /-}$ ) (Fig. 5A), and ENCCs subsequently undergo cell death (Uesaka et al., 2008). To understand how elevated $\mathrm{Bcl}-\mathrm{xL}$ expression influences this pathological process, we examined the developmental sequences of gut colonization by ENCCs in $R e t^{9 / B c l-x L}$ fetuses. No obvious differences were observed between $\operatorname{Ret}^{9 / B c l-x L}$ and Ret $^{9 /-}$ fetal gut (Fig. 5A), indicating that Ret-Bcl-xL allele had little ameliorating effect on delayed hindgut colonization by ENCCs. ENCC progression along the gut was comparable in $\mathrm{Ret}^{\mathrm{Bcl}-x \mathrm{LL} /+}$ and WT fetuses, demonstrating that elevated expression of Bcl-xL has no impact on ENCC migration in a nonpathological context either. The result also suggests that the Ret- $B c l-x L$ allele has no dramatic effect on ENCC proliferation, which is one of the major driving forces in ENCC progression (Flynn et al., 2007; Landman et al., 2007). We also examined whether elevated expression of Bcl-xL influences Ret gene expression. No significant difference was detected in Ret mRNA levels between $\mathrm{Ret}^{9 /-}$ and $\mathrm{Ret}^{9 / B c l-x L}$ enteric plexus (normalized values of Ret mRNA in $\mathrm{Ret}^{9 /-}$ and $R e t^{9 / B c l-x L}$ were 1.07 and 1.03, $n=3$ ). Taken collectively, Ret$B c l-x L$ allele did not exert any significant effects on migration, proliferation, and Ret expression in ENCCs, strongly suggesting that the biological function of $\mathrm{Bcl}-\mathrm{xL}$ is confined to its prosurvival action in ENS development.

Detailed morphological examination of the adult ENS (P60) of $R e t^{9 / B c l-x L}$ mice uncovered no significance differences in the total number of enteric neurons (WT and $R e t^{9 / B c l-x L}$ mice were $833 \pm 26$ and $801 \pm 19$ cells per $\mathrm{mm}^{2}$, respectively, $n=6$ ) or in the proportion of major neuronal subtypes in the colon when compared with WT (Fig. 6A). Almost all of the Ret ${ }^{9 / B c l-x L}$ mice developed normally and survived beyond 84 weeks, a sharp contrast to Ret $^{9 /-}$ mice, which showed growth retardation (average body weight at 1 month: WT, $17.4 \pm 0.2 \mathrm{~g}$ : $\mathrm{Ret}^{9 /-}, 13.5 \pm 0.9 \mathrm{~g}$; $\operatorname{Ret}^{9 / B c l-x L}, 16.4 \pm 0.7 \mathrm{~g}$ ) and early postnatal death (mortality rate $23 \%$ between P5 and P31) (Fig. 6B). Thus, Ret-Bcl- $x$ L allele significantly prevented lethality in Ret hypomorphic mice (log-rank test; $p=0.024)$. Although the surviving $R e t^{9 / C F P}$ mice tended to have lower stool frequency, wet stool weight, and stool water content than WT, Ret $t^{9 / B c l-x L}$ mice did not show similar tendencies toward impairment of gut motility (Fig. 6C). Together, these findings reveal that Ret- $B c l-x L$ allele allows morphologically and functionally normal ENS formation, demonstrating a striking preventive effect of prosurvival gene expression in a HSCRcausing condition.

\section{Discussion}

HSCR is a complex congenital disorder with a multifactorial etiology, but mutations in the RET gene appears to be the major cause for HSCR. Especially, a hypomorphic RET allele is highly associated with the vast majority of isolated HSCR, which comprises two-thirds of all HSCR. Mice carrying a hypomorphic Ret allele reproduce the genetic and phenotypic characteristics of isolated HSCR (Uesaka et al., 2008), and developmental analysis shows that hypomorphic Ret alleles impair the migration and survival of ENCCs, leading to intestinal aganglionosis in the distal colon. In this study, we addressed the significance of cell death in HSCR pathogenesis by inhibiting ENCC death in a Ret hypomorphic state in vivo by genetically elevating Bcl-xL expression in ENCCs. Surprisingly, this genetic manipulation allowed not only the survival of enteric neurons but also the formation of morphologically and functionally normal ENS despite the fact that the effect of Bcl-xL was restricted to the prevention of cell death and did not exert any effects on cell migration or proliferation. These results indicate that, even though ENCC migration is delayed during embryogenesis, there is a certain developmental time window that allows Ret hypomorphic ENCCs to compensate for the 
A

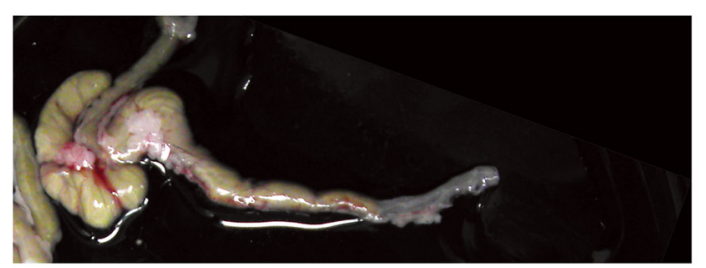

B
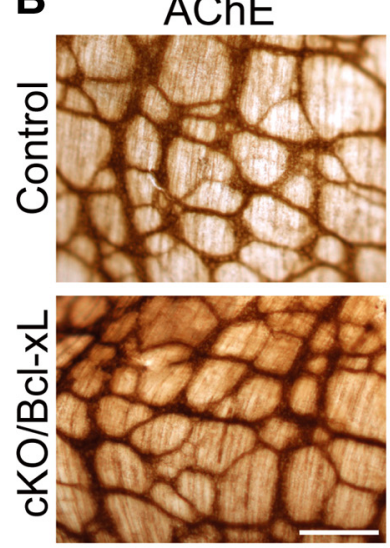

C

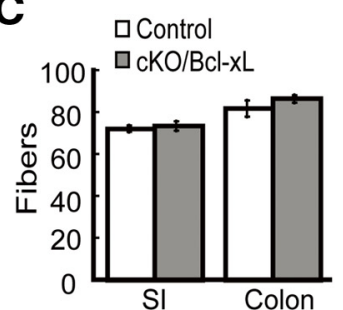

D Calretinin/CFP
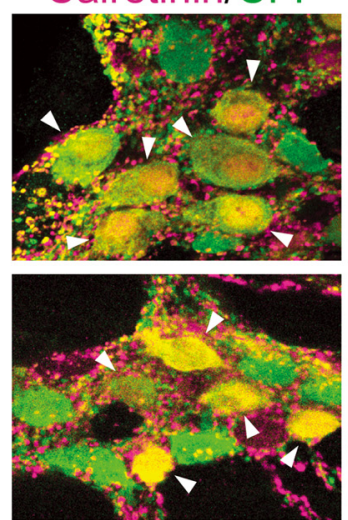

E

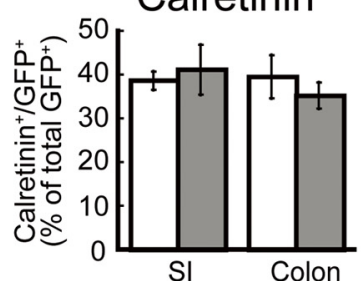

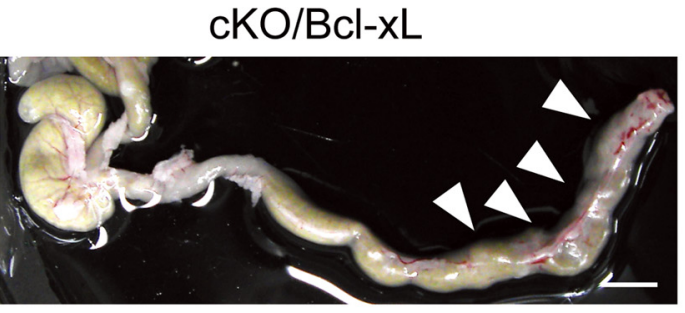
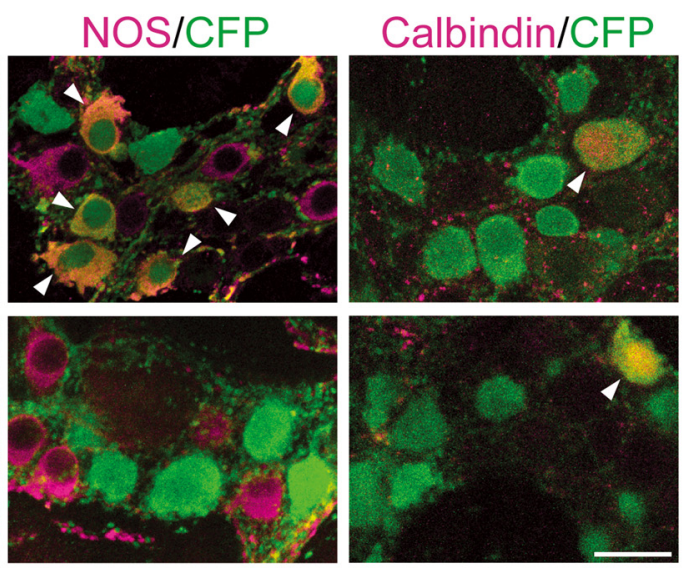

NOS

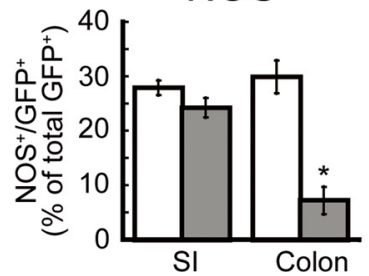

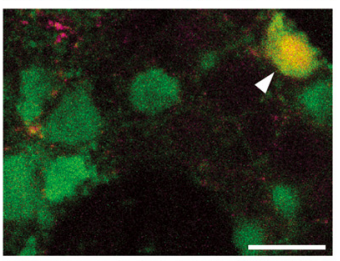

Calbindin

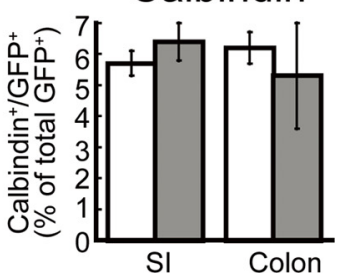

Figure 3. RET signaling is required for the expression of NOS in enteric ganglia of the colon. $A$, Whole-mount preparations of the colon from control and cKO/BCl-xL. The arrowheads indicate the gut regions with packed accumulation of feces. $\boldsymbol{B}$, AChE staining of $\mathrm{P} 60$ colon from control and cKO/BCl-xL mice. 4-OHT was injected at E15.5 into pregnant mothers. $C$, Quantitative analysis of fiber density in the ENS revealed no differences between the control and $\mathrm{KKO} / \mathrm{BCl}-\mathrm{xL}$ mice. Error bars indicate SEM $(n=3)$. $\boldsymbol{D}$, Immunohistochemistry for calretinin, NOS, and calbindin on P60 myenteric plexus of the colon. $E$, Quantification of the percentage of calretinin-, NOS-, and calbindin-positive neurons coexpressing CFP of the control (white bars) or cKO/BCl-xLmice (gray bars) in the myenteric plexus of the small intestine (SI) and colon. In the colon, $\mathrm{CKO} / \mathrm{BCl}-\mathrm{xL}$ mice show significantly fewer NOS-positive neurons than control mice. Error bars indicate SEM $(n=3)$. ${ }^{*} p<0.05$. Scale bars, $A, 5 \mathrm{~mm} ; \boldsymbol{B}, 200 \mu \mathrm{m} ; \mathbf{D}, 20 \mu \mathrm{m}$.

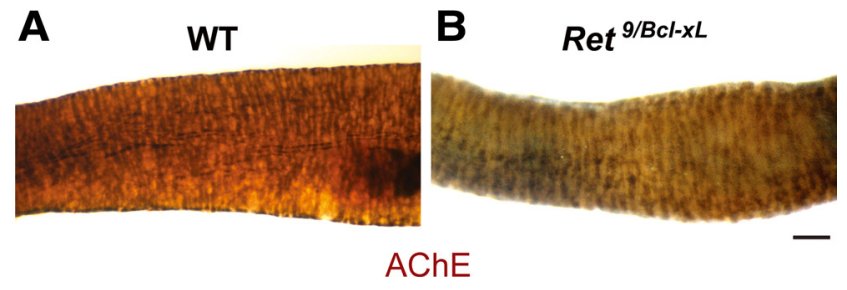

Figure 4. Elevated expression of $B C l-x L$ prevents the emergence of aganglionosis in Ret $t^{9 /-}$ mice. $\boldsymbol{A}, \boldsymbol{B}$, Whole-mount AChE histochemical analysis of the colon from WT $(\boldsymbol{A})$ and $\operatorname{Ret}^{9 / B C-x L}$ $(B)$ mice (PO). Elevated expression of $B C l-x L$ rescued ENS formation in the distal colon of the HSCR mouse model. Scale bar: (in $B), A, B, 200 \mu \mathrm{m}$.

migratory delay and complete their task of constituting the functional ENS so long as their survival is guaranteed. This is particularly striking considering that ENCC migration deficits have long been considered as crucial pathogenetic events in HSCR. We propose that ENCC death is central to the pathogenesis of shortsegment HSCR occurring as an isolated trait. It should also be noted, however, that some types of HSCR, especially a longsegment type, can arise as a result of more complex deficits involving delayed migration, reduced proliferation, and impaired survival and differentiation of ENCCs. Further analyses are therefore necessary to determine the principal cause for intestinal aganglionosis for those cases.

The survival of enteric neurons in the colon is critically dependent on Ret and Gfr $\alpha 1$, presumably through their actions in the mediation of GDNF signaling (Uesaka et al., 2007, 2008). The survival of colonic neurons is also Ret dosage dependent, as many ENCCs die in the colon in Ret hypomorphic mice. Those pathological enteric neuronal deaths occur in a nonapoptotic manner. Although the mechanisms underlying the ENCC death are not fully defined, several crucial features have been revealed by in vitro studies. GDNF deprivation induces death of colonic neurons in culture, and this cell death is not blocked by either pan-caspase inhibitor or Bax deficiency. Interestingly, however, Bcl-xL overexpression can inhibit ENCC death (Uesaka et al., 2007). In this study, we showed that effects of Bax and Bcl-xL on enteric neuronal death in vitro are conserved in vivo. While Bax deletion had negligible effects on the death of Ret-deficient ENCCs, Bcl-xL exerted a strong prosurvival effect on those cells. Overexpression of $\mathrm{Bcl}-\mathrm{xL}$ or its closest homolog, $\mathrm{Bcl}-2$, promotes not only neuronal survival (Garcia et al., 1992; Allsopp et al., 1993; Martinou et al., 1994; Farlie et al., 1995; Gonzalez-Garcia et al., 1995; Parsadanian et al., 1998) but also proliferation and migration of myocytes (Limana et al., 2002) ansd tumor cells (Du et 

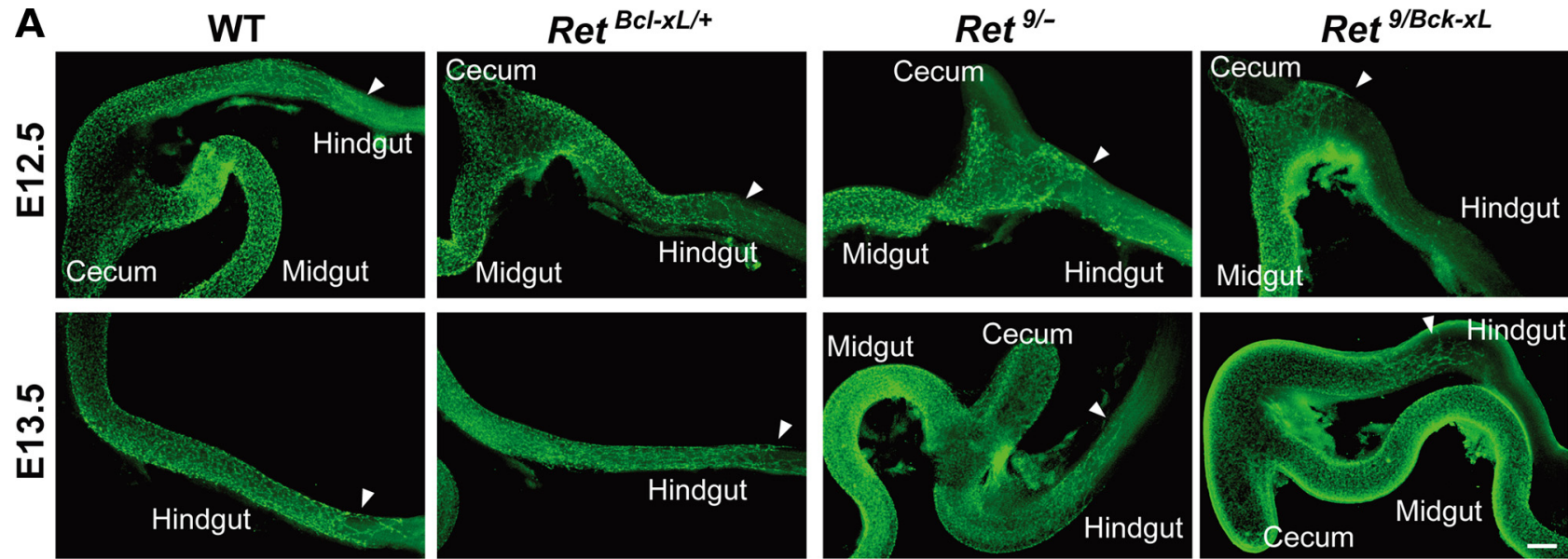

Sox10

B

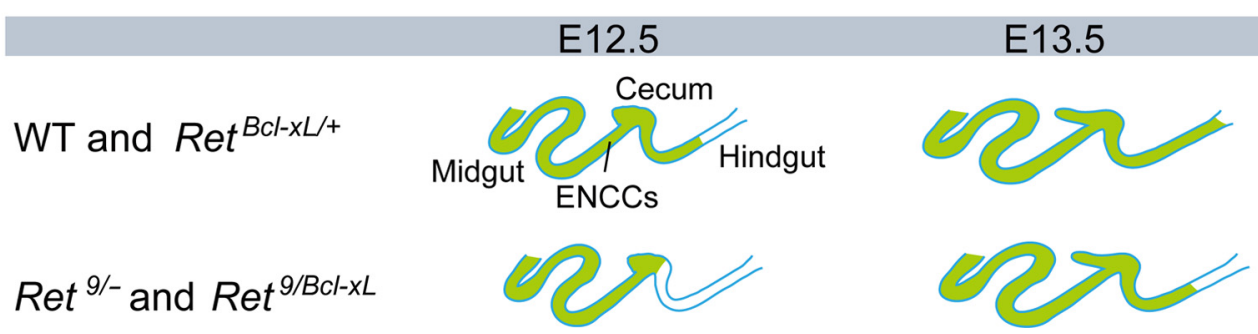

Figure 5. Elevated expression of BCl-xL has little effect on the delay in hindgut colonization in HSCR model mice. A, Sox10-labeled ENCCs (green) in the developing gut in WT, Ret ${ }^{B C-x L /+}$, Ret ${ }^{9 /-}$, and $\operatorname{Ret}^{9 / B C-1-x L}$ fetuses at E12.5 (top) and E13.5 (bottom). The migratory behavior of ENCCs in Ret ${ }^{9 / B c-x L}$ fetuses was indistinguishable from that seen in Ret $t^{9 /-}$ fetuses, indicating that elevated expression of $\mathrm{BCl}-\mathrm{xL}$ does not affect hindgut colonization by ENCCs. Arrowheads depict the front of the migrating ENCCs. B, Schematic drawing showing ENCCs (green) migration in the gut of WT, $\operatorname{Ret}^{B C-x L /+}, \operatorname{Ret}^{9 /-}$, and $\operatorname{Ret}^{9 / B C l-x L}$ fetuses. Scale bar, $200 \mu \mathrm{m}$

al., 2007), respectively. In the case of ENCCs, however, elevated expression of $\mathrm{Bcl}-\mathrm{xL}$ had no overt effects on the migration or proliferation of those cells and functioned specifically to promote their survival in vivo. The effect of $\mathrm{Bcl}-\mathrm{xL}$, therefore, appears to be distinct and dependent on expression levels and cell types.

The strong prosurvival effect of Ret$B c l-x L$ allele in ENCCs has also provided vital information toward a deeper understanding of ENS development. First, although colonic neuronal death occurs following the inactivation of Ret or Gfr $\alpha 1$, little is known about whether neuronal death also occurs physiologically during ENS development. In most parts of the nervous system, neuronal apoptosis is abundant during development (Oppenheim, 1991), which is a crucial step in determining the final neuronal numbers. In developing ENS, neuronal apoptosis is undetectable (Gianino et al., 2003; Kruger et al., 2003), but the possibility remains that enteric neurons may die in a nonapoptotic manner. This possibility, however, was strongly contradicted by the observation that there was no increase in the numbers of enteric neurons in $\operatorname{Ret}^{B c l-x L /+}$ mice. Neuronal death in the ENS may therefore occur only in
A

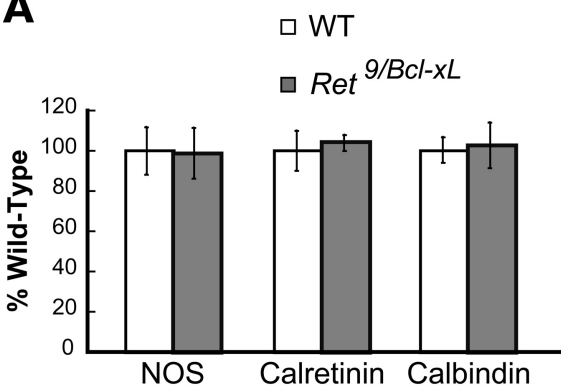

B $\quad \cdots R e t^{9 /-}$
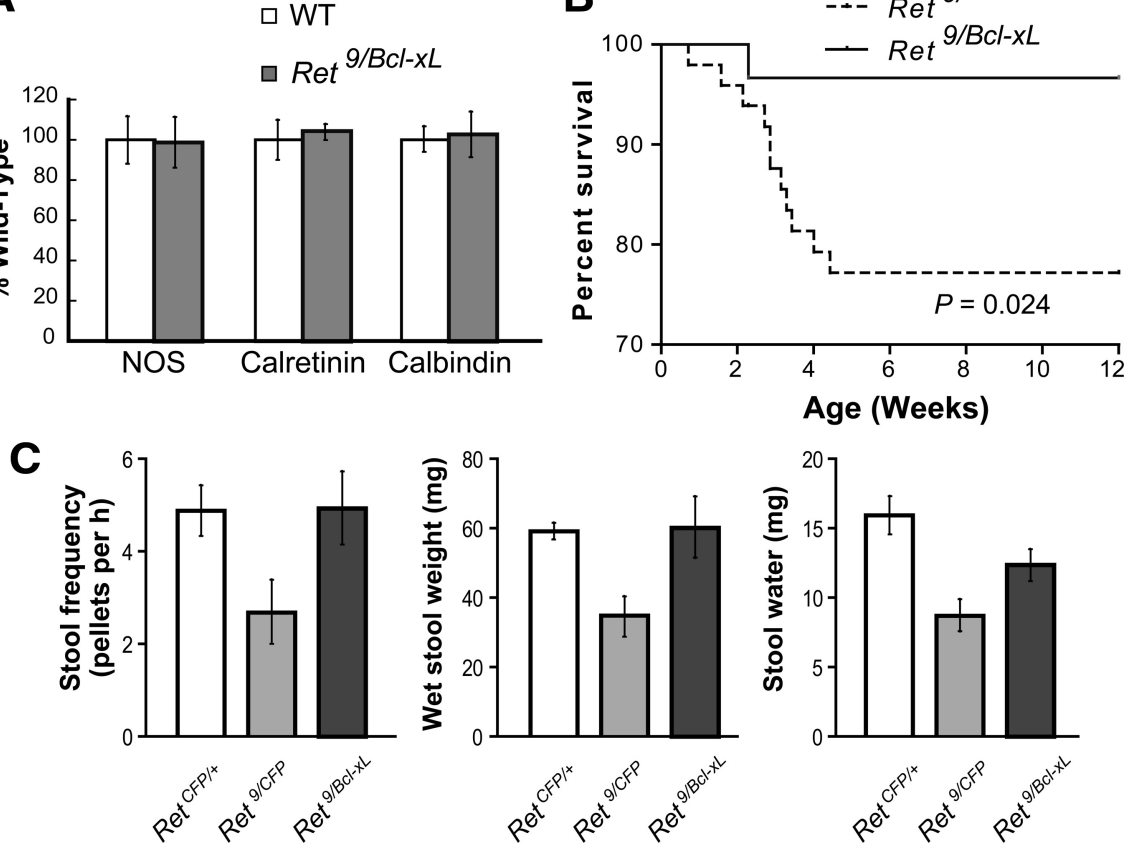

Figure 6. The immunohistochemical and functional properties of rescued enteric neurons are normal in the colon of $\operatorname{Ret}^{9 / B C l-x L}$ mice. $A$, Densities of enteric neurons identified by the immunoreactivities of NOS, calretinin, and calbindin did not change significantly between WT and Ret $^{9 / B C l-x L}$ mice. The data are presented as a percentage of WT neurons expressing each marker. Error bar indicates SEM $(n=3)$. B , Survival rate of $\operatorname{Ret}^{9 /-}(n=48)$ and $\operatorname{Ret}^{9 / B C-x L}(n=30)$ mice after birth. Ret-Bcl-xL allele significantly prevented lethality in Ret hypomorphic mice (log-rank test; $p=0.024)$. C, Surviving Ret ${ }^{9 / C F P}$ mice tended to have lower stool frequency, wet stool weight, and stool water content than WT, but Ret ${ }^{9 / B C l-x L}$ mice did not show such a tendency toward impairment of gut motility. Error bars indicate $\operatorname{SEM}(n=5)$. 
pathological conditions during development. Although it is still possible that the levels of Bcl-xL elevation in our study were not high enough to inhibit nonapoptotic cell death in the ENS, we favor the view that naturally occurring neuronal death is absent in the ENS and that the ENS employs other developmental processes, such as precursor proliferation, to generate appropriate numbers of neurons (Gianino et al., 2003). Second, the protection of Ret-deficient cells against cell death by the Ret-Bcl-xL allele, for the first time, afforded us an opportunity to examine the significance of the RET tyrosine kinase beyond its role in neuronal survival. A striking reduction in the NOS-expressing population and gut malfunction observed in the rescued Retdeficient mice demonstrates that RET is required for the functional maturation of the ENS, including subtype specification and perhaps neural circuit formation as well. It is currently unknown why NOS-expressing neurons are specifically affected by RET deletion at E15.5. As distinct enteric neuronal populations are born at given time windows during development (Pham et al., 1991; Chalazonitis et al., 2008), the influence of RET on neuronal subtype differentiation may be dependent on the timing of inactivation and be observed in most neuronal subtypes. Studies using Ret-inactivation at various developmental time points in a Ret- $B c l-x L$ background will be needed to resolve this issue.

The current major treatment for HSCR is surgical resection of the aganglionic segment of the gut. After surgery for HSCR, some patients continue to suffer from fecal incontinence (Menezes and Puri, 2006). It is unclear whether postoperative morbidity is related to the surgery or to potentially abnormal function of the residual ENS. In Ret hypomorphic mice, mere blockage of ENCC death led to formation of the functional ENS, and no obvious fecal incontinence was detected in the rescued animals. This observation sheds a light on new approaches to block ENCC death as an approach to the prevention of HSCR. Pharmacological enhancement of ENCC survival may one day be used as prophylaxis against HSCR.

\section{References}

Airaksinen MS, Saarma M (2002) The GDNF family: signalling, biological functions and therapeutic value. Nat Rev Neurosci 3:383-394.

Allsopp TE, Wyatt S, Paterson HF, Davies AM (1993) The proto-oncogene bcl-2 can selectively rescue neurotrophic factor-dependent neurons from apoptosis. Cell 73:295-307.

Amiel J, Sproat-Emison E, Garcia-Barcelo M, Lantieri F, Burzynski G, Borrego S, Pelet A, Arnold S, Miao X, Griseri P, Brooks AS, Antinolo G, de Pontual L, Clement-Ziza M, Munnich A, Kashuk C, West K, Wong KK, Lyonnet S, Chakravarti A, et al. (2008) Hirschsprung disease, associated syndromes and genetics: a review. J Med Genet 45:1-14.

Angrist M, Bolk S, Thiel B, Puffenberger EG, Hofstra RM, Buys CH, Cass DT, Chakravarti A (1995) Mutation analysis of the RET receptor tyrosine kinase in Hirschsprung disease. Hum Mol Genet 4:821-830.

Attie T, Pelet A, Edery P, Eng C, Mulligan LM, Amiel J, Boutrand L, Beldjord C, Nihoul-Fekete C, Munnich A, Ponder BAJ, Lyonnet S (1995) Diversity of RET proto-oncogene mutations in familial and sporadic Hirschsprung disease. Hum Mol Genet 4:1381-1386.

Badner JA, Sieber WK, Garver KL, Chakravarti A (1990) A genetic study of Hirschsprung disease. Am J Hum Genet 46:568-580.

Baloh RH, Enomoto H, Johnson EM Jr, Milbrandt J (2000) The GDNF family ligands and receptors - implications for neural development. Curr Opin Neurobiol 10:103-110.

Burzynski G, Shepherd IT, Enomoto H (2009) Genetic model system studies of the development of the enteric nervous system, gut motility and Hirschsprung's disease. Neurogastroenterol Motil 21:113-127.

Chalazonitis A, Rothman TP, Chen J-X, Gershon MD (1998) Agedependent differences in the effects of GDNF and NT-3 on the development of neurons and glia from neural crest-derived precursors immunoselected from the fetal rat gut: expression of GFR $\alpha$ - 1 in vitro and in vivo. Dev Biol 204:385-406.
Chalazonitis A, Pham TD, Li Z, Roman D, Guha U, Gomes W, Kan L, Kessler JA, Gershon MD (2008) Bone morphogenic protein regulation of enteric neuronal phenotypic diversity: relationship to timing of cell cycle exit. J Comp Neurol 509:474-492.

Deckwerth TL, Elliott JL, Knudson CM, Johnson EM Jr, Snider WD, Korsmeyer SJ (1996) BAX is required for neuronal death after trophic factor deprivation and during development. Neuron 17:401-411.

Du YC, Lewis BC, Hanahan D, Varmus H (2007) Assessing tumor progression factors by somatic gene transfer into a mouse model: $\mathrm{Bcl}-\mathrm{xL}$ promotes islet tumor cell invasion. PLoS Biol 5:e276.

Emison ES, McCallion AS, Kashuk CS, Bush RT, Grice E, Lin S, Portnoy ME, Cutler DJ, Green ED, Chakravarti A (2005) A common sex-dependent mutation in a RET enhancer underlies Hirschsprung disease risk. Nature 434:857-863.

Enomoto H, Crawford PA, Gorodinsky A, Heuckeroth RO, Johnson EM Jr, Milbrandt J (2001) RET signaling is essential for migration, axonal growth and axon guidance of developing sympathetic neurons. Development 128:3963-3974.

Farlie PG, Dringen R, Rees SM, Kannourakis G, Bernard O (1995) bcl-2 transgene expression can protect neurons against developmental and induced cell death. Proc Natl Acad Sci U S A 92:4397-4401.

Flynn B, Bergner AJ, Turner KN, Young HM, Anderson RB (2007) Effect of Gdnf haploinsufficiency on rate of migration and number of enteric neural crest-derived cells. Dev Dyn 236:134-141.

Garcia I, Martinou I, Tsujimoto Y, Martinou JC (1992) Prevention of programmed cell death of sympathetic neurons by the bcl-2 proto-oncogene. Science 258:302-304.

Gianino S, Grider JR, Cresswell J, Enomoto H, Heuckeroth RO (2003) GDNF availability determines enteric neuron number by controlling precursor proliferation. Development 130:2187-2198.

Gonzalez-Garcia M, Garcia I, Ding L, O'Shea S, Boise LH, Thompson CB, Nunez G (1995) bcl-x is expressed in embryonic and postnatal neural tissues and functions to prevent neuronal cell death. Proc Natl Acad Sci U S A 92:4304-4308.

Gould TW, Yonemura S, Oppenheim RW, Ohmori S, Enomoto H (2008) The neurotrophic effects of glial cell line-derived neurotrophic factor on spinal motoneurons are restricted to fusimotor subtypes. J Neurosci 28:2131-2146.

Grice EA, Rochelle ES, Green ED, Chakravarti A, McCallion AS (2005) Evaluation of the RET regulatory landscape reveals the biological relevance of a HSCR-implicated enhancer. Hum Mol Genet 14:3837-3845.

Hearn CJ, Murphy M, Newgreen D (1998) GDNF and ET-3 differentially modulate the numbers of avian enteric neural crest cells and enteric neurons in vitro. Dev Biol 197:93-105.

Hofstra RM, Wu Y, Stulp RP, Elfferich P, Osinga J, Maas SM, Siderius L, Brooks AS, vd Ende JJ, Heydendael VM, Severijnen RS, Bax KM, Meijers C, Buys CH (2000) RET and GDNF gene scanning in Hirschsprung patients using two dual denaturing gel systems. Hum Mutat 15:418-429.

Kruger GM, Mosher JT, Tsai YH, Yeager KJ, Iwashita T, Gariepy CE, Morrison SJ (2003) Temporally distinct requirements for endothelin receptor B in the generation and migration of gut neural crest stem cells. Neuron 40:917-929.

Landman KA, Simpson MJ, Newgreen DF (2007) Mathematical and experimental insights into the development of the enteric nervous system and Hirschsprung's disease. Dev Growth Differ 49:277-286.

Limana F, Urbanek K, Chimenti S, Quaini F, Leri A, Kajstura J, Nadal-Ginard B, Izumo S, Anversa P (2002) bcl-2 overexpression promotes myocyte proliferation. Proc Natl Acad Sci U S A 99:6257-6262.

Lyster DJ, Bywater RA, Taylor GS (1995) Neurogenic control of myoelectric complexes in the mouse isolated colon. Gastroenterology 108:1371-1378.

Martinou JC, Dubois-Dauphin M, Staple JK, Rodriguez I, Frankowski H, Missotten M, Albertini P, Talabot D, Catsicas S, Pietra C, Huarte J (1994) Overexpression of BCL-2 in transgenic mice protects neurons from naturally occurring cell death and experimental ischemia. Neuron 13:1017-1030.

Menezes M, Puri P (2006) Long-term outcome of patients with enterocolitis complicating Hirschsprung's disease. Pediatr Surg Int 22:316-318.

Miller TM, Moulder KL, Knudson CM, Creedon DJ, Deshmukh M, Korsmeyer SJ, Johnson EM Jr (1997) Bax deletion further orders the cell death pathway in cerebellar granule cells and suggests a caspase-independent pathway to cell death. J Cell Biol 139:205-217.

Natarajan D, Marcos-Gutierrez C, Pachnis V, de Graaff E (2002) Require- 
ment of signalling by receptor tyrosine kinase RET for the directed migration of enteric nervous system progenitor cells during mammalian embryogenesis. Development 129:5151-5160.

Oppenheim RW (1991) Cell death during development of the nervous system. Annu Rev Neurosci 14:453-501.

Parisi MA, Kapur RP (2000) Genetics of Hirschsprung disease. Curr Opin Pediatr 12:610-617.

Parsadanian AS, Cheng Y, Keller-Peck CR, Holtzman DM, Snider WD (1998) Bcl- $\mathrm{X}_{\mathrm{L}}$ is an antiapoptotic regulator for postnatal CNS neurons. J Neurosci 18:1009-1019.

Pham TD, Gershon MD, Rothman TP (1991) Time of origin of neurons in the murine enteric nervous system. J Comp Neurol 314:789-798.

Qu ZD, Thacker M, Castelucci P, Bagyanszki M, Epstein ML, Furness JB (2008) Immunohistochemical analysis of neuron types in the mouse small intestine. Cell Tissue Res 334:147-161.

Sang Q, Young HM (1998) The identification and chemical coding of cholinergic neurons in the small and large intestine of the mouse. Anat Rec 251:185-199.

Sang Q, Williamson S, Young HM (1997) Projections of chemically identified myenteric neurons of the small and large intestine of the mouse. J Anat 190:209-222.

Schuchardt A, D’Agati V, Larsson-Blomberg L, Costantini F, Pachnis V (1994) Defects in the kidney and enteric nervous system of mice lacking the tyrosine kinase receptor Ret. Nature 367:380-383.

Seri M, Yin L, Barone V, Bolino A, Celli I, Bocciardi R, Pasini B, Ceccherini I,
Lerone M, Kristoffersson U, Larsson LT, Casasa JM, Cass DT, Abramowicz MJ, Vanderwinden JM, Kravcenkiene I, Baric I, Silengo M, Martucciello G, Romeo G (1997) Frequency of RET mutations in long- and short-segment Hirschsprung disease. Hum Mutat 9:243-249.

Shindler KS, Latham CB, Roth KA (1997) bax deficiency prevents the increased cell death of immature neurons in $b c l-x$-deficient mice. J Neurosci 17:3112-3119.

Skinner MA (1996) Hirschsprung's disease. Curr Probl Surg 33:389-460.

Taraviras S, Marcos-Gutierrez CV, Durbec P, Jani H, Grigoriou M, Sukumaran M, Wang LC, Hynes M, Raisman G, Pachnis V (1999) Signalling by the RET receptor tyrosine kinase and its role in the development of the mammalian enteric nervous system. Development 126:2785-2797.

Uesaka T, Jain S, Yonemura S, Uchiyama Y, Milbrandt J, Enomoto H (2007) Conditional ablation of GFRalphal in postmigratory enteric neurons triggers unconventional neuronal death in the colon and causes a Hirschsprung's disease phenotype. Development 134:2171-2181.

Uesaka T, Nagashimada M, Yonemura S, Enomoto H (2008) Diminished Ret expression compromises neuronal survival in the colon and causes intestinal aganglionosis in mice. J Clin Invest 118:1890-1898.

White FA, Keller-Peck CR, Knudson CM, Korsmeyer SJ, Snider WD (1998) Widespread elimination of naturally occurring neuronal death in Baxdeficient mice. J Neurosci 18:1428-1439.

Young HM, Hearn CJ, Farlie PG, Canty AJ, Thomas PQ, Newgreen DF (2001) GDNF is a chemoattractant for enteric neural cells. Dev Biol 229: 503-516. 